Motrivivência Ano XXIV, No 38, P. 40-58 Jun./2012

\title{
FORMAÇÃO E ATUAÇÃO PEDAGÓGICA NO PROGRAMA SEGUNDO TEMPO: reflexões sobre o fazer cotidiano do professor
}

\author{
Allusson Carvalho de Araújo \\ Loreta Melo Bezerra Cavalcanti ${ }^{2}$ \\ Rafael Miranda Tassitano ${ }^{3}$ \\ Eliene Pereira de Lacerda ${ }^{4}$ \\ Maria Cecília Marinho Tenório ${ }^{5}$
}

\begin{abstract}
RESUMO
O presente artigo tem por intenção refletir sobre a prática pedagógica dos professores atuantes do Programa Segundo Tempo - PST, tendo como parâmetro as diretrizes do programa e a formação profissional dos envolvidos no processo. Os dados analisados são frutos de coletas por questionário somados a registros de observação da equipe em visitações in loco em convênios localizados nos estados de Pernambuco e Sergipe. As considerações apontam para a dificuldade de operacionalização das diretrizes do Programa Segundo Tempo, sobretudo nas questões metodológicas da oferta de prática esportiva, mesmo considerando a formação requerida nas diretrizes do segundo tempo.
\end{abstract}

Palavras-Chave: Esporte; Formação; Prática pedagógica.

1 Professor Assistente I do Departamento de Educação Física da UFRN. Consultor do Ministério do Esporte para o programa segundo tempo desde 2008.Contato: allyssoncarvalho@hotmail.com.

2 Professora de Educação Física da IFRN. Consultor do Ministério do Esporte para o programa segundo tempo desde 2008.Contato: loretamelo@gmail.com.

3 Professor Assistente III do Departamento de Educação Física da UFRPE. Consultor do Ministério do Esporte para o programa segundo tempo desde 2008.Contato: rafael_tassitano@hotmail.com.

4 Professor Assistente I da FAculdade de Educação Física da UFG. Consultora do Ministério do Esporte para o programa segundo tempo entre 2008-2010.Contato: elienemorango@yahoo.com.br.

5 Professora Assistente I do Departamento de Educação Física da UFRPE. Consultora do Ministério do Esporte para o programa segundo tempo desde 2010.Contato: mariaceciliatenorio@gmail.com. 


\section{O ESPORTE E A PRÁXIS PEDAGÓGICA}

Cotidianamente evidenciam-se discursos relatando que de nada vale especular teoricamente as questões educacionais se não destinarmos nosso foco para a prática pedagógica. Neste contexto, o que nos chama atenção é pensar a ação pedagógica como elemento que fomenta as discussões acadêmicas e que sem ela estes discursos poderiam perder seu sentido.

Acreditamos que é este caminho que nos propomos a percorrer nestas páginas. Pensar a prática pedagógica, as impressões dos profissionais sobre sua ação docente e as oportunidades que estes têm de pensar seu fazer profissional em suas formações serão nossas telas de apreciação.

Para isso, consideramos que toda ação pedagógica é propositiva e, mesmo que esta não esteja explicitamente declarada, é necessário compreender o compromisso ao qual se filia o profissional, pois, atuar como educador é, ou deveria ser, no nosso entender, ter compromisso com o próximo e com todos.

As questões educativas, por sua inserção na realidade, justificam-se na medida em que se entende o processo educativo como meio de transformação social. Para além do formato atual do cenário educativo brasileiro pautado no racionalismo, sobreposição de saberes, tecnicismo e transmissão de conteúdos desarticulados. Morin (2003, p. 72) nos aponta uma concepção de educação para a formação da cidadania. Segundo ele, a educação é espaço promotor de acesso à cultura historicamente acumulada pelo ser humano, mas também é espaço de preparar o homem para o futuro.

Nesse sentido, tendo o esporte como elemento recorrente nas propostas educacionais, a Secretaria Nacional de Esporte Educacional (SNEED) propõe o Programa Segundo Tempo, como ação do Ministério do Esporte que visa atender crianças e adolescentes expostos aos riscos sociais, respeitando o artigo $n^{\circ} 217$ da constituição federal que versam sobre o dever do estado em fomentar práticas esportivas à população.

Tendo como objetivo central democratizar o acesso ao esporte educacional de qualidade, como forma de inclusão social, ocupando o tempo ocioso de crianças e adolescentes em situação de risco social, este projeto pressupõe mudança e ancora-se na expectativa de melhoria da qualidade de vida de seus beneficiados por meio da oferta de práticas esportivas educacionais, estimulando crianças e adolescentes a manter uma interação efetiva que contribua para o seu desenvolvimento integral (BRASIL, 2008).

O projeto pauta-se em princípios como cidadania, diversidade, inclusão social e democracia para promover a formação de valores educativos (GAYA \& TORRES, 2008), construindo, para tanto, uma diretriz teórico-metodológica bem delimitada a partir de 2008. A construção desse alinhamento teórico-prático na política pública em questão demandou um esforço coletivo de grupos de pesquisadores de várias áreas do país para pensar uma matriz conceitual passível de operacionalização.

O desafio seguinte a esta etapa é fortalecer um novo pensar e, sobretudo, um novo fazer sobre a pedagogia do esporte que resista à tradição da repetição irrefletida e do engessamento docente às estratégias de ensino do fenômeno esportivo.

As diversas influências que o esporte sofreu, enquanto manifestação cultural de instituições sociais, constituem uma 
aderência a um perfil militarista e calistênico, por vezes, irrefletidamente transpassado para cenários educacionais. Considerando o esporte como manifestação emblemática das práticas corporais que ainda resguarda resquícios do Método Desportivo Generalizado que influenciou o Brasil a partir da década de 40 (ASSIS, p. 2001) e refletindo sobre o modo como ele vem sendo tratado em sua prática pedagógica, é possível observar disparidades ainda existentes entre a produção acadêmica, a sua pedagogia e a dificuldade de sua concretização como prática pedagógica democrática.

Sobre este fato Fensterseifer (2001) aponta o distanciamento evidenciado na área como se fosse possível pensar uma dicotomia entre teoria e prática. De acordo com este autor:

Temos, então, de um lado, as diferentes linhas teóricas patrocinadas por profissionais que têm suas verdades no plano do verbalismo e disputam adesões às suas "seitas" e, de outro, aqueles que experimentam mudanças práticas sem, no entanto sustentá-las no plano teórico, não resistindo à mordacidade da crítica solapadora dos primeiros. Resulta disso o imobilismo que tem caracterizado, salvo raras exceções, o trabalho pedagógico no campo da educação física. (FENSTERSEIFER, 2001, p, 35)

De fato, compreendemos que a proposição metodológica que fuja dos padrões reificados em nossa área possa derivar resistências, por vezes inconscientes, pela ausência de reflexão sobre o fazer pedagógico. $\mathrm{O}$ que nos recorre à mente nesses momentos, e que de certo modo nos impulsiona a continuar, é que as formulações metodológicas que se apresentam atualmente são apenas reflexos das lacunas herdadas por proposições metodológicas anteriores, que obtêm seu mérito ao instigar o redimensionamento pedagógico constante.

A proposta encaminhada pelo Programa Segundo Tempo partiu de um princípio que privilegia o jogo como uma forma incidental de aprendizado. A proposição denominada de Sistema de Aprendizagem e Desenvolvimento Esportivo (SADE) dialoga os aspectos do desenvolvimento humano com o aprendizado dos esportes. Segundo Greco e Silva,

O processo metodológico de ensino de diferentes modalidades esportivas no Programa Segundo Tempo sugerido enfatiza primeiramente as formas de ensino-aprendizagem incidental e posteriormente os denominados processos intencionais, formais de ensino-aprendizagem direcionados para meIhorar a compreensão tática do aluno, em síntese, desenvolver sua capacidade de jogo. (GRECO \& SILVA, 2008, p. 88)

Diferentemente dos tradicionais modelos de ensino do esporte, o SADE avança da esquizofrenia das jogadas ensaiadas e repetições com vistas a um padrão motor ideal para considerar os aspectos ambientais das práticas esportivas e valor educacional do jogo.

Ancorados na certeza de que as proposições apontadas nas diretrizes do Programa Segundo Tempo sugerem um uma modificação no fazer pedagógico do ensino do esporte no Brasil, no propomos a refletir sobre a prática pedagógica dos professores atuantes do programa Segundo Tempo, tendo como parâmetro as diretrizes do programa e a formação profissional dos envolvidos no processo.

Este objetivo operacionaliza-se em algumas questões que para nós são caras neste esforço de compreender o processo 
de oferta do esporte à população brasileira, são elas:

a. A formação profissional indicada para compor os recursos humanos no Programa Segundo Tempo garante uma oferta de prática esportiva de qualidade aos beneficiados? Que outros fatores podem influenciar este aspecto?

b. Os profissionais envolvidos no Programa Segundo Tempo compreendem e aplicam a proposta pedagógica indicada nas formações oportunizadas pelo Ministério do Esporte?

C. A prática pedagógica observada no cotidiano do Programa Segundo Tempo garante a especificidade teórico-metodológica da proposta? Existem outras referências que povoam as práticas observadas?

A pesquisa indaga a realidade dos convênios do Programa Segundo Tempo nos estados de Pernambuco e Sergipe, considerando como universo de análise os convênios da Prefeitura Municipal de Petrolina (40 núcleos) e da Prefeitura Municipal de Aracaju (26 núcleos). O universo de investigação foi delimitado pelo critério de funcionamento no período de 20082009, momento da construção da proposta pedagógica do Programa Segundo Tempo, envolvendo a capacitação dos profissionais envolvidos no atendimento aos beneficiados e posterior operacionalização da práxis pedagógica nos núcleos.

O instrumento de coleta de dados foi um questionário composto por questões abertas e fechadas que versam sobre a formação continuada ofertada na proposta do Programa Segundo Tempo e a compreensão e operacionalização das diretrizes do programa. Foram recolhidos e analisados 34 instrumentos, respondidos por coordenadores de núcleos, monitores e coordenadores gerais, que representam $17 \%$ dos recursos humanos que compõem as ações do Segundo Tempo nos Convênio atuantes.

A intenção de investigar todos os atores envolvidos no Programa Segundo Tempo reside na compreensão de que a Prática Pedagógica para Souza (2006) não é uma atividade de uma só pessoa, ela tem características de coletividade, ela se configura pela investigação na sua totalidade, na sua perspectiva geral e específica no âmbito escolar e também outros espaços institucionais. Todo este processo tem a direção de humanização, onde esta faz conexões com outras práticas e pode estar na transformação ou na manutenção do sistema educacional.

Mesmo considerando que nosso foco de pesquisa são os atores que estão diretamente vinculados ao desenvolvimento de atividades esportivas, entendemos que a prática docente é apenas uma das dimensões da Prática Pedagógica interconectada com a prática gestora, prática discente e a prática gnosiológica e/ou epistemológica. A Prática Docente faz parte da Prática Pedagógica, mas não se reduz a ela. A intencionalidade é o que diferencia a Prática Pedagógica da Prática Docente, ela não se reduz à escola, e se caracteriza também nos movimentos sociais.

A prática docente se caracteriza pelo processo pelo qual o professor realiza sua ação educativa com a intenção de prover ensino-aprendizagem, porém, não se limita à regência. A prática educativa envolve organização, gestão, ensino e pesquisa, partindo de uma finalidade que é a de 
humanização. Diante do grau de complexidade e de intencionalidade que permeia a prática docente emergem dimensões que rodeiam e configuram este processo como a dimensão política, a dimensão do conhecimento e a dimensão pedagógica e cultural (SOUZA, 2006).

Os dados coletados a partir das questões fechadas comporão um perfil dos profissionais envolvidos na proposta enquanto que as questões que remetem à formação e ao fazer pedagógico comporão núcleos de sentido das falas dos profissionais que serão problematizados com vistas a compreender a organização do trabalho pedagógico do Programa Segundo Tempo na realidade dos Estados de Pernambuco e Sergipe.

\section{FORMAÇÃO E PRÁTICA PEDAGÓGICA: MAPEANDO A REALIDADE}

As duas categorias analíticas levantadas estão diretamente relacionadas ao discutirmos as dificuldades encontradas no dia a dias das vivências do PST. Identificamos o complexo campo de investigação que se apresenta no universo educacional, compreendendo e percebendo as diferentes práticas que acontecem institucionalmente. Nesse momento, o olhar foi direcionado à formação e à prática docente, por compreender que estes elementos compõem o foco do estudo onde se localiza nosso universo maior, a Prática Pedagógica.

Ao pensarmos sobre a questão da Prática Pedagógica aderimos ao pensamento de Souza (2006) ao concebê-la como prática coletiva, multidimensional e intencional. Nas palavras deste autor

Encara-se a prática pedagógica como uma ação coletiva, por isso argumentada e realizada propositadamente com objetivos claros que possam vir a garantir a realização da finalidade da educação e de certos objetivos de acordo com os problemas em estudo, explicitamente assumidos por uma instituição (SOUZA, 2007 p.179).

A prática pedagógica ainda é definida como sinônimo de diversos termos como, apresenta os estudos de Souza Júnior (2001), dentre práticas, ações, processos e fazeres: prática didática, prática educacional, prática docente, prática educativa, prática escolar. Este termo surge na tentativa de superar dualidades e dicotomias na Educação: ensino x aprendizagem, conteúdo $\mathrm{x}$ forma, professore $x$ aluno, teoria $x$ prática, etc.

Para o Coletivo de Autores (1992) a prática pedagógica surge de necessidades sociais concretas. Já Sánchez Vásquez (2007) compreende esse conceito como uma dimensão da prática social que pressupõe a relação teoria-prática e que é orientada por objetivos, finalidades e conhecimentos, na qual uma dimensão ideal formula anseios em que está presente a subjetividade humana e uma dimensão material constituída pelo conjunto de meios e instrumentos com os quais se exerce a ação.

No que tange à formação docente demarca-se que a preocupação com a formação do educador, que teve seu impulso inicial no século XVI, a partir da tensão da reforma protestante e contra-reforma católica, vem progressivamente se intensificando no sentido de aprimorar-se e comprometer-se com a qualidade do ensino.

Observando-se que até a década de 1980 do século passado a tradição da formação de professores trabalhava reforçando a lógica da segregação entre especialistas da área educacional e professores da educação 
básica (MELO \& BORBA, 2006), a problemática recorrente na formação profissional pedagógica situava-se exatamente na bipartição entre Teoria - Prática. Considerando os primeiros como produtores de conhecimento, mesmo que distantes da prática pedagógica, e o segundo grupo como os responsáveis pela aplicabilidade desses conhecimentos na educação básica. A educação ocasionou apropriação irrefletida de conhecimentos que poderiam ser mais bem aproveitados na intervenção pedagógica se na sua concepção já dialogassem com a realidade de ensino.

Na especificidade da formação em Educação Física a regra desse distanciamento persiste e agrava-se pela constituição vivencial dos temas por ela tratados que possibilita a recorrente repetição de práticas pedagógicas calistênicas e distantes das proposições pedagógicas que envolvem as instituições de ensino ou projetos sociais que tematizam as práticas corporais.

Os saberes docentes necessários para o ensino das práticas corporais, e em especial o esporte, foram sistematizados historicamente no Brasil por instituições de formação de professores de educação física $^{7}$, no entanto, tem-se identificado na fala dos professores ao longo dos anos o afastamento destes saberes dialogados na formação do professor com a prática pedagógica (BORGES, 2005). A autora coloca claramente que "o sentimento de adquirir, na etapa da formação, conhecimentos que não serve na prática pedagógica é largamente compartilhado pelos docentes" (BORGES, 2005, p. 176).
Pensando na possibilidade da compreensão dos saberes docentes como elementos que extravasam o currículo da formação inicial do professor recorremos a Tardif (2002) que apresenta uma tipologia baseada na origem social dos saberes. $\mathrm{Na}$ sua compreensão os saberes docentes se categorizam em: saberes pessoais, que envolvem aprendizados familiares, históricos de vida e internalização de valores; saberes da formação escolar, remetendo-se à formação educacional que antecede a sua formação profissional; saberes da formação docente, incluindo a formação inicial e continuada; saberes oriundos dos programas escolares, que remetem a recorrência a livros e manuais didáticos e; finalmente os saberes da experiência, provenientes da prática pedagógica cotidiana.

Ao constatar que o Programa Segundo Tempo privilegia profissionais com formação em Educação Física e/ou estudantes da área para aderirem aos recursos humanos do programa, e que estes profissionais são apresentados a um modelo específico de trabalho, segundo as diretrizes teórico-metodológica do programa, através de capacitações sistemáticas realizadas pelo Ministério do Esporte, considera-se importante refletir sobre o impacto desta formação continuada tendo em vista os demais saberes que pluralizam a aprendizagem constante da ação docente.

Nesse sentido, conhecer os profissionais envolvidos no processo e indagar-lhes o que lhes parece significativo no processo de edificação e operacionalização da proposta pedagógica do Programa Segundo Tempo

6 Inicialmente concebida envolvo a influência das Instituições militares e posteriormente vinculadas Instituições de Ensino Superior (IES). 
surge-nos como essencial para formular núcleos de sentido neste loco de ação docente.

Na tentativa de compreender o perfil dos sujeitos envolvidos no processo e partindo da realidade investigada, percebe-se que nem todos os coordenadores de núcleo têm formação superior em Educação Física. As outras formações identificadas no grupo investigado são as de Letras, História e pedagogia com algumas pós-graduações lato sensu, tais como psicopedagogia (01), Educação e meio Ambiente (01) e Metodologia da Língua portuguesa (01). Dentre os profissionais que atuam como coordenadores de núcleos que tem formação em Educação física destacando que cinco (05) deles possuem pós-graduação em lato sensu, sendo um (1) deles especialista em Metodologia da EF para educação básica, dois (2) em Fisiologia do exercício aplicada ao esporte e à saúde, um (1) em Didática e Metodologia do Ensino Superior e um (1) em Psicomotricidade.
A maioria dos monitores envolvidos no processo são estudantes de Educação Física, com exceção de quatro (04) deles, que possuem formação até o ensino médio.

Esta realidade é compreendida a partir do contexto de formação em Educação Física nas áreas atendidas pelos convênios investigados, bem como, pelas peculiaridades de cada realidade a que se adere o convênio nos seus aspectos administrativos e culturais.

Fazendo referência às experiências vividas como indicadores de saberes alicerçados em momentos anteriores à sua formação profissional, quase todos profissionais afirmaram ter tido contato com o fenômeno esportivo seja como atleta de clubes, prática esportiva escolar, ou práticas informais em praças ou ruas. Acreditamos que esse tipo de experiência pode ser seminal na representação da prática esportiva de um sujeito, influenciando, inclusive, sua ação docente no ensino do esporte.

Tabela 1 - Experiência acerca da prática esportiva.

\begin{tabular}{cc}
\hline EXPERIÊNCIA ESPORTIVA & ENVONVIDOS \\
Aulas de Educação Física escolar & $70,5 \%$ \\
Ex-atleta de clube & $14,7 \%$ \\
Ex-atleta escolar & $52,9 \%$ \\
Prática informal & $26,4 \%$ \\
Nenhuma & $2,9 \%$
\end{tabular}

No que tange à experiência no ensino do esporte, os profissionais se manifestaram quanto à atuação junto à escola públicas ou privadas, ensino do esporte em clubes, no próprio Programa Segundo Tempo, bem como em outros projetos sociais.

Tabela 2 - Experiência acerca do ensino do esporte.

\begin{tabular}{cc}
\hline ENSINO DO ESPORTE & ENVOLVIDOS \\
\hline Escolas públicas & $88,2 \%$ \\
Escolas privadas & $20,5 \%$ \\
Clubes & $17,6 \%$ \\
\hline Apenas no Programa Segundo Tempo & $8,2 \%$ \\
\hline Outros projetos Sociais & $14,7 \%$ \\
\hline
\end{tabular}


As informações sobre experiências pedagógicas enquanto praticante e professores dos sujeitos envolvidos na pesquisa nos alertam para o amplo envolvimento dos mesmos com o ensino do esporte em diferentes contextos o que pode propiciar maior articulação de saberes no trato deste conteúdo. A busca por esses dados, parte da argumentação de que os saberes docentes organizam-se a partir de enlaces que também resgatam suas vivências esportivas para aprender a ser docente.

A aprendizagem da profissão se alimenta de fontes plurais (história e trajetória de vida, formação escolar e experiências educativas, formação universitária, prática da profissão etc.) e que entre essas fontes, a experiência cotidiana do trabalho é a principal, pois é por meio dela que outros saberes adquiridos no decorrer da vida, da formação e da carreira são mobilizados, usados, avaliados, rejeitados e/ou conservados, mas transformados e adaptados (BORGES, 2005, p. 184).

É a partir desses últimos dados que residem as reflexões de manutenção ou distinção de uma atitude diferenciada do profissional que se propõem a engajar-se no Programa Segundo Tempo. Conforme é possível verificar, cerca de $90 \%$ das respostas que versam sobre experiências anteriores remetem ao cenário de ensino do esporte que remetem a cenários diferentes do Programa Segundo Tempo (PST) o que acarreta pensar que outras referências para o ensino do esporte povoam a prática pedagógica desses profissionais e que podem influenciar nas posturas pedagógicas dentro do PST.

Segundo outros estudos realizados, é possível perceber que geralmente os profissionais pouco modificam suas intervenções pedagógicas durante sua trajetória de docente (BASEl et al, 2008). A constatação pode indicar que o fazer docente se constrói no fazer cotidiano, como já indicamos, e que se consolidam com o passar do tempo. Considerando que isto não signifique imobilidade, propõe um modo operante de cada profissional difícil de ser desconsiderado, mas passível de ser re-elaborado.

Tanto no Brasil quanto em qualquer outro lugar, a experiência do trabalho cotidiano com os alunos parece ser, para os docentes, a principal fonte de aprendizagem da profissão e o local mesmo onde se edificam seus saberes profissionais e se constroem sua competência prática de ensino. Mas esses saberes da experiência também são plurais, como dizem os docentes, que falam de saberes relacionados aos conhecimentos específicos de educação física, por exemplo, conhecimentos relativos a diferentes modalidades esportivas, conhecimentos técnicos e pedagógicos aplicados ao ensino de um esporte qualquer, de competências e de savoir-faire, se saber se organizar, de saber planejar [...] (BORGES, 185).

Quase todos os profissionais envolvidos na pesquisa participaram de alguma capacitação do Ministério do Esporte ${ }^{7}$, com vistas a apresentar as diretrizes operacionais, teóricas e metodológicas do

7 A Secretaria Nacional de Esporte Educacional (SNEED) promoveu no ano de 2008 várias capacitações em diversas cidades do Brasil nas diversas regiões do país, ao total forma 48 turmas capacitadas que totalizaram a formação de 4. 481 profissionais envolvidos com o Programa Segundo Tempo (inseridos aqui os Coordenadores Pedagógicos e Setoriais). 
PST. Indagados sobre a relevância dos momentos que compuseram a capacitação, os profissionais destacam, dentre outras coisas, prioritariamente as vivências práticas oportunizadas naquele espaço de formação, bem como, a oportunidade de troca de experiências com outros profissionais que têm trabalhado em espaços distintos.
A partir do quadro abaixo é possível observar a prevalência destas posições que revelam a necessidade dos profissionais de uma formação voltada para a prática pedagógica. Que visualize as questões cotidianas dos núcleos e propicie uma aplicabilidade dos saberes tratados na capacitação.

Tabela 3 - Momentos considerados importantes na capacitação.

\begin{tabular}{|cc|}
\hline MOMENTO MAIS IMPORTANTE DA CAPACITAÇÃO & OPNIÕES \\
\hline Explanação sobre Metodologia de ensino & $8,2 \%$ \\
\hline Explanação sobre os fins educacionais do PST & $8,2 \%$ \\
Vivências práticas & $38,2 \%$ \\
\hline Trocas de experiências dos outros profissionais & $14,7 \%$ \\
\hline Abertura com a equipe do Ministério do Esporte & $2,9 \%$ \\
Não respondeu ou não participou & $8,2 \%$ \\
\hline Todos os momentos foram importantes & $17,6 \%$ \\
\hline
\end{tabular}

O formato da capacitação ofertada pelo Ministério do Esporte já reconhece esta necessidade de explicitar os procedimentos metodológicos em vivências práticas no sentido de dar consistência operacional ao aporte teórico produzido. Desse modo, reservam-se momentos de experimentação de jogos e atividades dentro da carga-horária da capacitação para socializar possibilidades de ação pedagógica que possam ser aproveitadas no cotidiano dos núcleos.

A receptividade desses momentos é visualizada quando indagados sobre quais os momentos da capacitação os professores consideram operacionalizáveis no contexto dos núcleos do PST. Cerca de 45\% dos profissionais apresentam as vivências práticas como elementos que são facilmente operacionalizados na realidade dos núcleos no que tange o ensino do esporte. Outro destaque dos profissionais foram as diretrizes para a democratização do esporte $(23,4 \%)$, notadamente, as questões que versam sobre inclusão, gênero, deficiente e sobre os princípios do esporte educacional.

Tabela 4 - Possibilidade de operacionalização da capacitação nos núcleos do PST.

\begin{tabular}{|cc|}
\hline QUESTÕES QUE PODEM SER & OPINIÕES \\
OPERACIONALIZÁVEIS NO NÚCLEO & $44,1 \%$ \\
\hline Vivências práticas & $23,4 \%$ \\
\hline Democratização das atividades & $2,9 \%$ \\
\hline Embasamento teórico & $14,7 \%$ \\
\hline Adaptação de aulas à realidade & $14,7 \%$ \\
\hline
\end{tabular}


Percebamos que o interesse em viver a intervenção pedagógica que se propõe em um projeto social educacional como o Programa Segundo Tempo pode, de um lado, recair na atualização do modelo tecnicista para o ensino do esporte, preocupado somente com as suas questões procedimentais, mas pode também, por outro lado, buscar promover a superação da dualidade teoria-prática a partir de uma reflexão sobre o fazer docente que se baliza em proposições educativas definidas.

É necessário superar a dualidade teoria-prática, de modo a possibilitar situações em que o professor reflita coletivamente sobre sua prática docente, não apenas a partir de das teorias pedagógicas já existentes, mas também produzindo saberes, estando engajados nas discussões recentes em torno da educação (MELO \& BORBA, 2006, p. 10).

Entendemos que no Programa Segundo Tempo, por sua intenção e formato da capacitação ofertada, ocorra à busca da superação de polarização teoria-prática.
Pois, em momentos articulados, as proposições teóricas, os princípios educacionais e os encaminhamentos metodológicos dialogam recursivamente, garantindo especificidades das temáticas elencadas, sem perder as junções necessárias para o fazer docente. Esta visão coaduna com o posicionamento dos profissionais capacitados em todo Brasil, que creditaram $93,2 \%$ de aprovação em relação aos temas e sua relevância para o exercício da Coordenação frente aos núcleos do Programa Segundo Tempo ${ }^{8}$.

Quando indagados sobre a utilização das atividades sugeridas no material didático fornecido pelo Ministério do Esporte, os profissionais investigados relatam adesão ao leque de opções de atividades propostas, mesmo argumentando as possibilidades de re-significar as práticas a partir do parâmetro colocado. É necessário esclarecer que na fala dos profissionais, os posicionamentos que apontam para o não uso das atividades justificam a partir da não adequação à realidade vivenciada por eles, seja por questões estruturais ou pedagógicas.

Tabela 5 - Utilização das sugestões de atividade presentes no material didático do Programa Segundo Tempo.

UTILIZAÇÃO DE ATIVIDADES SUGERIDAS NO MATERIAL DIDÁTICO DO PROGRAMA SEGUNDO TEMPO

OPINIÕES

Sim $88,2 \%$

Não $\quad 8,2 \%$

Não respondeu

Regressando às experiências junto atividades sugeridas no material didático. A constatação sempre fora contestada com argumentação de adaptação à realidade e, aos profissionais, em visitação aos núcleos, não foi possível perceber a utilização das

$2,9 \%$

8 Dados extraídos do Relatório das Capacitações desenvolvidas no ano de 2008, consolidado pela Coordenação Geral de Acompanhamento Pedagógico e Administrativo do Programa Segundo Tempo - CGAPAP, da Secretaria Nacional de Esporte Educacional - SNEED. 
neste sentido, os encaminhamentos destacados apontavam para uma leitura fiel da proposta em questão para a produção de uma releitura cabível dentro das diretrizes do PST, pois:

Entendemos que o professor não deve aplicar teoria na prática e, sim, (re) construir (reinventar) sua prática com referência em ações/experiências e em reflexões/teorias. É fundamental que essa apropriação de teorias se dê de forma autônoma e crítica, portanto, com ação de um sujeito, de um autor. (CAPARROZ \& BRACHT, 2007, p. 27)

A partir do instrumento de coleta de dados e de vivências junto aos núcleos do Programa Segundo Tempo verifica-se que a prática pedagógica do (a) professor(a) de Educação Física e outros profissionais capacitados para desenvolver as atividades do Programa Segundo Tempo (PST) se apresentam de forma pouco homogênia. Questionamentos, discussões, propostas, sucessos e fracassos estão presentes neste espaço que suscita estudos propositivos e participativos para educação a partir de intensas e diversas situações vivenciadas diariamente por esses profissionais. O esforço é de debruçarmos na busca de uma base de conhecimento sobre a organização destas práticas educativas no cotidiano escolar.

Tabela 6 - Como os professores estruturam e desenvolvem suas aulas.

\begin{tabular}{cc}
\hline ESTRUTURAÇÃO E DESENVOLVIMENTO DAS AULAS & OPINIÕES \\
Explanação do tema, atividade e debate de fechamento & $17,6 \%$ \\
Fundamentos e habilidades esportivas diversificadas e jogos & $29,4 \%$ \\
Aquecimento, desenvolvimento de fundamentos e volta à calma & $20,5 \%$ \\
Não deixa claros os procedimentos ou não respondeu & $32,3 \%$
\end{tabular}

$\mathrm{Na}$ fala dos profissionais, reservada as ênfases diferenciadas, percebe-se uma postura explicativa sobre as proposições de aulas e/ou atividades aos alunos. Esta constatação coaduna com outros estudos que apontam as formas de demonstração e de explanação e correção do movimento como estratégias mais recorrentes para ensino do esporte, como podemos perceber a partir do estudo de Basei (2008).

Ao falarem da utilização do método demonstrativo explicativo, podemos deduzir que os professores entendem o ensino dos esportes como ele apresenta-se na sociedade, institucionalizados/ normatizados, pois apresentam ao aluno formas de movimento e de execução de tarefas que limitam a capacidade criativa dos alunos, constituindo como reprodutores de conhecimento e não construtores, prática esta, possivelmente semelhante a que vivenciaram durante o seu curso de formação inicial. (BASEl et al, 2008, p. 1).

Nas instituições, em especial nas escolas onde existe a presença do $\mathrm{PST}^{9}$, para onde direcionamos nosso olhar, encontramos sujeitos sociais que se relacionam com

9 Todos os núcleos dos convênios analisados são sediados por escolas públicas municipais. 
essas diferentes práticas: docente, discente e gestora. Nestas práticas, se estabelecem relações que construirão um contexto sob a perspectiva de objetivos claros, na tentativa de superar as dificuldades que se apresentam como a construção de conhecimento e das discussões dos conteúdos pedagógicos que chegam às escolas elaboradas e organizadas por outras instituições.

Constatamos esse tipo de realidade ao indagar os profissionais sobre as formas que eles acreditam que deva ser encaminhado o aprendizado do esporte e como ele é operacionalizado no núcleo do PST onde atua.

Tabela 7 - Compreensão sobre o aprendizado do Esporte e operacionalização no Programa Segundo Tempo.

COMPREENSÃO SOBRE O APRENDIZADO DO ESPORTE E OPERACIONALIZAÇÃO NO NÚCLEO DO PST

\section{OPNIÕES}

$23,4 \%$

Com base na inclusão e não baseado na busca de talentos

Respeitando as individualidade e potencialidades de cada um de forma lúdica

\section{Ênfase educacional}

Ênfase técnica primeiramente e tática posterior mente, lógica progressiva.

\begin{tabular}{|cc|}
\hline Construção coletiva do jogo (regras, técnicas) & $5,8 \%$ \\
\hline Não respondeu ou não deixou claro & $11,7 \%$ \\
\hline A partir das diretrizes do PST & $2,9 \%$ \\
\hline Diversidade das práticas esportivas & $5,8 \%$ \\
Aulas teóricas para regras e limites & $2,9 \%$ \\
\hline
\end{tabular}

As idéias divergentes e com considerações pouco operacionais transparecem uma construção que resgata posturas subjetivas para compreender e tratar o esporte. Apesar de quase todos os núcleos de sentidos aproximarem-se dos elementos pedagógicos debatidos em formação do Programa Segundo Tempo, verifica-se pouca consistência do real encaminhamento metodológico para o ensino do esporte.

Recorremos a Souza (2007) para compreender o universo de ações sociais coletivas, que constitui a formação e intervenção humana. Este autor intenciona dar visibilidade às condições subjetivas e outras objetivas de todos/as em qualquer lugar do mundo. Neste sentido, torna-se recorrente o resgate das experiências vividas, incluindo a construção de valores sociais, para as re-mixar com as proposições pedagógicas atualmente apresentadas. Neste sentido é necessário destacar

a importância de se considerar o professor em sua própria formação, num processo de auto-formação, de reelaboração dos saberes iniciais em confronto com sua prática vivenciada. Assim seus saberes vão-se constituindo a partir de uma reflexão na e sobre a prática. Essa tendência reflexiva vem-se apresentando como um novo paradigma na formação de professores, sedimentando uma política de desenvolvimento pessoal e profissional dos professores (NUNES, 2001, p. 30).

Perguntados sobre a crença da diferença entre a proposta de ensino do 
Programa Segundo Tempo e outras práticas esportivas os profissionais investigados indicam perceber a diferença existente, fortalecendo nas argumentações o discurso sobre o caráter educacional da proposta em contraposição ao esporte de rendimento.

Tabela 8 - Diferença entre a proposta do PST e outras ofertas de prática

$\begin{array}{cc}\text { CRENÇA NA DIFERENÇA ENTRE A PROPOSTA DO PST E } & \text { OPINIÕES } \\ \text { OUTRAS OFERTAS DE PRÁTICA ESPORTIVAS } & 70,5 \% \\ \text { Sim } & 26,4 \% \\ \text { Não } & 2,9 \% \\ \text { Não respondeu }\end{array}$

A partir da fala dos profissionais reforça-se uma intuição latente. A de que é clara a compreensão dos princípios que regem o PST, mas, em contrapartida, é pouco nítida em termos metodológicos onde esta proposta se diferencia das demais. Pelas posturas evasivas nesse ponto e pelos apontamentos observados in loco em diversos núcleos, fica evidente a necessidade de investimento nessa apropriação de forma mais concreta.

Os motivos que constroem o cenário que aponta para a reduzida claridade metodológica mencionada anteriormente advêm, a nosso ver, de vários campos que permeiam desde uma resistência em reproduzir propostas metodológicas que se fizeram presentes ao longo da vida esportiva de cada um, passando por proposições que se apresentaram na formação inicial dos profissionais ou ainda nas apropriações formatadas ao longo da experiência docente.

Convictos de que não só as questões da apropriação dos saberes docentes interferem na ação pedagógica apontamos os estudos de Araújo e Amorim (2008) por entendem que as práticas pedagógicas são constituídas de elementos que se expressam e se diferenciam entre si de acordo com a realidade de cada espaço educativo, dos saberes, dos docentes e suas representações sociais sobre a finalidade da educação, na qual a compreensão destes se dará na relação com o todo e com as partes.

A prática docente está inserida no contexto social, principalmente no que se refere às políticas educacionais e a organização das instituições. As autoras supracitadas ressaltam que se deve subsidiar os professores (as) com condições sociais de ensino e de trabalho, sendo que, a realização das atividades deve-se ao enfrentamento entre o cotidiano escolar, as condições de trabaIho, a visão de mundo e do conhecimento epistemológico sobre o objeto de ensino e aprendizagem (ARAÚJO \& AMORIM, 2008).

No que se refere às condições de trabalho, os profissionais investigados expressaram duas dificuldades a serem superadas. Uma delas é a questão da infra-estrutura física que nem sempre atende às necessidades dos núcleos. A segunda questão diz respeito aos valores de pagamento pelo exercício docente no Programa Segundo Tempo. E sobre este ponto, os profissionais foram quase unânimes em declarar que não consideravam os valores compatíveis com suas atribuições profissionais e formações. 
Tabela 9 - Considerações sobre o valor de pagamento.

\begin{tabular}{cc} 
CONSIDERA O VALOR DE PAGAMENTO COMPATÍVEL & OPINIÕES \\
COM AS ATRIBUIÇÕES E FORMAÇÃO & $85,2 \%$ \\
Não & $2,9 \%$ \\
Sim & $2,9 \%$ \\
Em partes & $8,2 \%$ \\
\hline
\end{tabular}

Atrelados às opiniões, se localizam referências sobre responsabilidades e compromisso necessários para o bom desenvolvimento do projeto, bem como, agregam-se questões do quanto o trabalho é gratificante e do quanto contribui para a formação dos beneficiados.

A sensibilização dos profissionais envolvidos com o compromisso educacional proposto pelo Programa Segundo Tempo é perceptível. Atentos a sua função social, os profissionais buscam dialogar seus conhecimentos, limitações, formações e crenças com fins de uma oferta de prática esportiva comprometida com formação cidadã.

A prática pedagógica revela a possibilidade da interação social, por se encontrar num locus de manifestação mais amplo que é o da Educação. Assim, como ação social coletiva de um contexto, podendo este ser em diferentes instituições de educação formal ou não-formal, se constituir por intencionalidades. O necessário é alinhar as intenções, formações e crenças dos diversos atores que constroem o Programa Segundo Tempo no contexto brasileiro para alcançarmos melhores sínteses na prática esportiva democratizada.

Pensarmos sobre a questão da Prática Pedagógica é segundo Souza (2006) concebermos como prática coletiva, por isso é entendida como práxis, multidimensional e intencional. E exatamente por esse entendimento de prática coletiva e enraizada no contexto é hora de indagarmos, revisitando Borges (2005, p. 186), se "não é tempo então, de repensar essa formação à luz das exigências da prática dos docentes de profissão?".

Frente aos dados coletados e vivências oportunizadas junto aos núcleos em Pernambuco e Sergipe é esta a questão que nos cerca. A sedução agora é pensar de que forma atender a essas demandas em uma formação continuada e reflexiva.

\section{CONSIDERAÇÕES SOBRE A PRÁTICA PEDAGÓGICA: AVANÇOS NO PENSAR A PRÁTICA?}

A ação educativa para Libâneo (2001) inclui saberes e modos de agir como conceitos, teorias, habilidades, técnicas, procedimentos, estratégias, atitudes, crenças, valores, preferências, adesões, que precisam ser comunicados como condição de continuidade da sociedade e produção de outros saberes e modos de agir. E a escola, bem como outros espaços sociais que se pretendem educativos, é um lugar que os alunos aprendem a desenvolver a razão crítica e a se construírem como sujeitos autônomos e críticos

Nesta lógica para Souza (2006) a prática pedagógica é entendida como práxis, é institucional, multidimensional e 
fundamentalmente intencional. Este autor aponta a necessidade da recognição ${ }^{10} \mathrm{e}$ a reinvenção ${ }^{11}$ do conceito de Prática pedagógica para se compreender de forma adequada a formação de professores como resultante de uma Práxis Pedagógica.

A Práxis Pedagógica supõe uma Pedagogia que ajude os seus profissionais a posicionar a instituição, enquanto instituição cultural formadora de novos profissionais, inclusive para a educação, no interior do contexto social histórico, escolhendo as suas intencionalidades e os conteúdos pedagógicos a serem trabalhados ou conhecimentos a serem profissionais mais competentes enquanto exercício profissional constitui uma das dimensões humanas do sujeito humano (SOUZA, 2006, p. 12).

A Educação tem a função de contribuir para a construção da humanidade dos seres humanos. Ela é toda atividade cultural na qual se dará o processo de ensino-aprendizagem, a reflexão em um instrumento essencial da luta entre os diferentes grupos socioculturais.

A prática docente sendo o processo pelo qual o docente realiza sua ação educativa com a intenção de prover ensino-aprendizagem, não se limita à regência. A Práxis Pedagógica é a inter-relação de práticas de sujeitos sociais formadores que objetivam a formação de sujeitos que desejam ser educados respondendo aos requerimentos de uma determinada sociedade em um momento histórico, produzindo conhecimentos que ajudem a compreender e atuar nessa mesma sociedade e na realização humana dos sujeitos (SOUZA, 2006, p. 11).

A práxis pedagógica tanto pode ser realizada nas escolas, nas casas, nas ruas, nas fábricas, nos sítios, nos movimentos sociais e também nos núcleos do PST. Mas, sobretudo e de modo especial, nas atividades educativas desenvolvidas na formação de professores, trabalhadores/as adolescentes, adultos, jovens; que assuma a construção do humano como central. O essencial da práxis formadora de professores é o enriquecimento cultural dos futuros profissionais da escolarização.

Machado e Pereira (2008) destacam em seus achados que a concepção de Prática perpassa pelo sentido de Prática Docente, no Fazer Pedagógico e no Saber Docente no qual o objetivo central recai sob a atuação do professor. Nesse sentido, a Prática Pedagógica também aparece sendo discutida como elemento inicial para, posteriormente, se discutir a Formação Profissional. Há uma relação direta da prática pedagógica com a formação de professores, pois ao se discutir inicialmente a prática pedagógica, ela está associada à formação continuada, que por sua vez, apresenta-se como subsídio fundamental para que os professores reflitam sobre suas práticas buscando alternativas para transformá-las e construir, assim, novas práticas.

Observa-se que a formação profissional requerida para atuar no Programa Segundo tempo contribui para que os profissionais compreendam a proposta do

10 Para Souza (2006) a recognição é o processo de construção de conhecimento ou de conteúdos pedagógicos a serem elaborados na busca de outra compreensão, interpretação e explicação das realidades naturais e culturais.

11 Reinvenção é a capacidade de enriquecer e emocionar-se de educadores, gestores e educandos, de agir no interior da escola e buscar formas de interação. 
programa, mas que, no entanto deve dialogar com uma formação que alerte para a especificidade do mesmo. A diversidade de influências que intervêm na forma de compreender do esporte aponta para uma multiplicidade de forma de organização do seu ensino. Acreditamos que os saberes das experiências esportivas como atletas ou de metodologias acessadas no momento da formação básica em Educação Física podem influenciar na absorção ou não da Proposta do Programa Segundo Tempo.

Estas considerações podem ser confirmadas com a constatação dos dados coletados em que se verifica que os profissionais envolvidos compreendem a proposta do PST no que tange à sua filosofia de inclusão e democratização do esporte, mas não demonstram ter se apropriado da proposta metodológica para o ensino do esporte nas diretrizes do Programa Segundo Tempo.

Nas observações feitas em diversos núcleos também é possível observar a interpenetração de outras referências teórico-metodológicas povoando as práticas docentes nos núcleos do segundo tempo.

Acreditamos que a formação continuada, dentro e fora do Programa Segundo Tempo, possibilita diversas alternativas de pensar junto para solucionar um problema, que por muitas vezes não é só nosso, e que contribuirá na qualidade das práticas docentes desenvolvidas nos núcleos do PST. Paralelamente a diversidade de referências pode ocasionar cruzamento de posturas que nem sempre dialogam com tranqüilidade.

O cuidado com a capacitação do Programa Segundo Tempo tem priorizado o diálogo entre as diretrizes conceituais e os encaminhamentos metodológicos, no entanto pensar sobre a prática se torna necessário com os profissionais atuantes no processo educacional dos núcleos.

Ao nosso olhar, faz-se necessário garantir um espaço para pensar sobre a especificidade do projeto, para que o comprometimento com a oferta do esporte seja compatível com o esforço de formular a proposta pedagógica do programa. Um espaço em que, já postas às referências que demarcam a proposta e vivenciado as possibilidade metodológicas, fosse possível debater sobre os avanços e aplicabilidades das mesmas nos diversos contextos onde se inserem o PST. Paralelo a este momento faz-se necessário buscar, nos profissionais envolvidos, respostas a essas propostas de forma que estes apresentem as novas demandas de trabalho pedagógico, considerando que lá se localiza o foco do esforço em pensar uma política pública.

É necessário que os saberes sistematizados no cotidiano dos núcleos sejam socializados entre os professores para, numa espécie de validação e construção coletiva de um saber que é edificado pela prática, permitir a procura de referenciais teóricos que Ihes possibilitem o aprofundamento e diálogo reflexivo baseado não somente na experiência individual, por vezes limitada, mas, sobretudo, na discussão coletiva.

Um passo importante no sentido de garantir a fala dos profissionais envolvidos e fortalecer o envolvimento com estes foi dado ao regionalizar as capacitações por meio da Equipes Colaboradoras. Este esforço possibilita maior contato com a realidade e o respeito à especificidade das diversas regiões do Brasil. Elementos como estes formulam identidade aos convênios mesmo garantindo o diálogo com as diretrizes do Programa Segundo Tempo, ao passo que possibilitam o feedback das práticas 
pedagógicas dos núcleos para pensar os temas que podem emergir da realidade. Este ciclo oportuniza a formação continuada dos profissionais envolvidos no Programa Segundo Tempo, garantindo aderência dos envolvidos à proposta e a consolidação do programa.

\section{REFERÊNCIAS}

ARAÚJO, Maria de Jesus Vasconcelos e AMORIM, Roseane Maria de. Formação Continuada e a Prática Pedagógica dos (as) Professores (as) alfabetizadores (as): desafios e perspectivas para um novo tempo. In: RECIFE, Prefeitura. Educadores em Rede: articulando a diversidade e constituindo singularidades. Diretoria Geral de Ensino e Formação Docente, 2008.

ASSIS, Sávio. A Reinvenção do Esporte: possibilidade da prática pedagógica. Campinas: Autores Associados, 2001.

BASEl, Andréia Paula. Et al. A prática pedagógica dos professores de Educação Física e a influencia do esporte: da formação à atuação profissional. [On line]. Disponível in: http://www.efdeportes.com/ Revista Digital - Buenos Aires - Año 13 - No 123 - Agosto de 2008.

BORGES, Cecília. A Formação dos Docentes de Educação Física e seus Saberes Profissionais. In: BORGES, Cecília \& DESBIENS, Jean-François (Orgs.). Saber, Formar e Intervir para uma Educação Física em Mudança. São Paulo: Autores Associados, 2005.

BRASIL, Ministério do Esporte. Manual do

Programa Segundo Tempo. Brasília: ME/Secretaria Nacional de Esporte Educacional, 2008.
CAPARROZ, Francisco Eduardo \& BRACHT, Valter. O tempo e o lugar de uma didática da educação física. Revista Brasileira de Ciências do Esporte. Campinas, v. 28, n. 2, p. 21-37, janeiro de 2007.

COLETIVO DE AUTORES. Metodologia do Ensino da Educação Física. São Paulo: Cortez, 1992.

FENSTERSEIFER, Paulo Evaldo. A Educação

Física na Crise da Modernidade. Ijuí: Unijuí, 2001.

GAYA, Adroaldo \& TORRES, Lisiane. A Cultura Corporal do Movimento Humano e o Esporte Educacional. In: BRASIL, Ministério do Esporte. Material didático para o processo de capacitação do Programa Segundo Tempo. Brasília: ME/Secretaria Nacional de Esporte Educacional, 2008.

GRECO, Juan Pablo \& SILVA, Siomara A. A metodologia de ensino dos esportes no marco do programa segundo tempo. In: BRASIL, Ministério do Esporte. Material didático para o processo de capacitação do Programa Segundo Tempo. Brasília: ME/Secretaria Nacional de Esporte Educacional, 2008.

LIBÂNEO, José Carlos. A Prática Pedagógica da Educação Física nos Tempos e Espaços Sociais. In: XIII Congresso Brasileiro de Ciências do Esporte - Conbrace. Caxambu - Minas Gerais, 2001.

MACHADO, Lizandre e PEREIRA, Eliene Lacerda. O Estado da Arte na Pesquisa em Educação: focalizando a prática pedagógica. In: Anais do II Encontro de Pesquisa Educacional em Pernambuco: objeto de investigação e inserção social - II EPEPE. Recife, 2008.

MELO, José Pereira \& BORBA, Sandra Maria. A formação continuada de 
professores. In: MELO, José Pereira \& BORBA, Sandra Maria. A importância do ensino de arte e educação física na escola. Natal: UFRN/PAIDEIA/MEC, 2006.

MELO, Silvia Sousa de. Formação de

Professores: caminhos e descaminhos da prática docente. Monografia apresentada no curso de Pedagogia do Centro de Ciências Humanas e educação. Universidade da Amazônia. Belém/ PA. 2001. Disponível: www.nead. unama.br/site/bibdigital/monografias/ FORMACAO_PROFESSORES.pdf Acessado em: 28/09/08

MORIN, Edgar. Os Sete Saberes Necessários à Educação do Futuro. $8^{\mathrm{a}}$ ed. Trad. Catarina Eleonora F. da Silva e Jeanne Sawaya. São Paulo: Cortez; Brasília: UNESCO, 2003.

NUNES, Cecília Maria Fernandes. Saberes docentes e formação de professores: um breve panorama da pesquisa brasileira. In: Educação \& Sociedade, ano XXII, $\mathrm{n}^{\circ}$ 74, Abril/2001.

SÁNCHEZ VÁSQUEZ, Adolfo. Filosofia da Práxis. $1^{\mathrm{a}}$. Ed. Buenos Aires: consejo Latinoamericano de Ciências Sociales - CLACS; Tradução María Encarnación Moya. São Paulo: Expressão Popular, Brasil, 2007.

SOUZA JúNIOR, Marcílio. A Prática

Pedagógica da Educação Física nos Tempos e Espaços Sociais. In: XIII Congresso Brasileiro de Ciências do Esporte - Conbrace. Caxambu - Minas Gerais, 2001.

SOUZA, João Francisco de. E a Educação Popular?? Quê??: uma pedagogia para fundamentar a educação, inclusive escolar, necessária ao povo brasileiro. Recife: Bagaço, 2007.
SOUZA, João Francisco de. Prática Pedagógica e Formação de Professores. Ensaio para concorrer ao Cargo de Professor Titular do Departamento de Métodos e Técnicas de Ensino do Centro de Educação da Universidade Federal de Pernambuco: 2006.

TARDIF, Maurice. Saberes Docentes e Formação Profissional. Petrópolis, RJ: Vozes, 2002. 
TRAINING AND EDUCATIONAL PERFORMANCE IN SECOND TIME PROGRAM: reflections on the daily tasks of the teacher

\begin{abstract}
This article is intended to reflect on the pedagogical practice of teachers working Program Second Time - PST, having as parameter the program guidelines and training of those involved in the process. The data analyzed were collected by questionnaire fruits of records added to the observation team on-site visitations covenants located in the states of Pernambuco and Sergipe. Considerations point to the difficulty of operationalizing the Second Half Program guidelines, especially in methodological issues in the supply of sports, even considering the training required in the guidelines of the second half.
\end{abstract}

Keywords: Sport; Training; Pedagogical practice.

Recebido em: abril/2012

Aprovado em: julho/2012 